This is a PDF file of an unedited manuscript that has been accepted for publication in Renewable \& Sustainable Energy Reviews. The manuscript will undergo copyediting, typesetting, and review of the resulting proof before it is published in its final form. Please note that during the production process errors may be discovered which could affect the content, and all legal disclaimers that apply to the journal pertain.

The final version will be available at: http://doi.org/10.1016/j.rser.2018.04.077

\title{
Public Policies for Smart Grids in Brazil
}

\author{
Guilherme de A. Dantas ${ }^{1}$, Nivalde J. de Castro ${ }^{1}$, Luis Dias ${ }^{2}$, Carlos Henggeler Antunes ${ }^{3}$, Pedro \\ Vardiero ${ }^{1}$, Roberto Brandão ${ }^{1}$, Rubens Rosental ${ }^{1}$, Lucca Zamboni ${ }^{4}$ \\ ${ }^{1}$ GESEL, Federal University of Rio de Janeiro, Brazil \\ ${ }^{2}$ Faculty of Economics, CEBER and INESC Coimbra, University of Coimbra, Portugal \\ ${ }^{3}$ Dept. of Electrical and Computer Engineering and INESC Coimbra, University of Coimbra, Portugal \\ ${ }^{4}$ EDP Energias do Brasil, São Paulo, Brazil
}

\begin{abstract}
The evolution of existing electricity grids to smart grids strongly relying on information and communication technologies will expectedly contribute to improving the system overall efficiency. However, the economic characteristics of the electricity sector tend to discourage investments in smart grids. In this context, it is understandable many countries have adopted incentive policies to foster the deployment of smart grids. It is noticeable that these policies vary depending on the specific characteristics of each country. Therefore, the design of specific public policies for Brazil must consider not only the motivations involved, but also the existing challenges for the implementation of smart grids and the socio-economic context. Moreover, the relevance of the proposed policies can be seen from different perspectives, which justifies the importance of eliciting information from multiple stakeholders for decision support purposes. This paper presents and assesses a set of policies identified by different stakeholders as having a potential major contribution for the development of smart grids in Brazil. The methodology to shape this set of policies consisted of a thorough literature review of international experiences combined with meetings with experts in several domains in order to identify the current situation and development prospects of smart grids in Brazil. An assessment of these policies was made by applying a Delphi questionnaire with the purpose of measuring their effectiveness in fulfilling the objectives associated with investments in smart grids. A first conclusion is that all policies were assessed as being positive taking into account each of the objectives. This means that the experts classified all policies as relevant to be adopted, differing only in the priority to be assigned to each one. The policies that were considered more relevant were: "Incentive Policies for Promoting Demand-Side Management, Distributed Generation and Storage", "Regulatory Changes to Foster Innovation in the Energy Sector" and "Regulation of New Business Models". Among the policies with the worst scores, "Mandatory Rollout of Smart Meters" and "Establishing Quality Standards for the Telecommunications Industry" were ranked as the two lower-ranked policies, i.e., they were assigned lower priority under all objectives.
\end{abstract}

\section{Keywords}

Delphi method, innovation, public policies, regulation, smart grids

\section{Introduction}

The evolution of existing electricity grids to smart grids strongly relying on information and communication technologies (ICT) will expectedly contribute to improving the system overall efficiency. 
This includes enhancing quality of service and technical/non-technical losses, saving operational costs, facilitating the penetration of dispersed generation based on renewable sources and deferring investments on generation and network reinforcement, while empowering consumers and making new business models, such as aggregators, to emerge. Smart grids will foster innovative demand-side management possibly profiting from dynamic price of electricity, diffusion of electric mobility, and the introduction of electricity storage systems [1]. However, the economic characteristics of the electricity sector, particularly with respect to the regulatory framework and traditional business models, tend to discourage investments in smart grids [2][3][4][5]. In this context, it is understandable many countries have adopted incentive policies to foster the deployment of smart grids [6][7]. The search for efficiency gains and the improvement of the quality of service offered by the electrical system are the main drivers for the development of smart grids in Brazil. Therefore, the discussion about the implementation of public policies nurturing these aims is relevant.

It is noticeable that these policies vary depending on the specific characteristics of each country [8][9]. Therefore, the design of specific public policies for Brazil must consider not only the motivations involved, but also the existing challenges for the implementation of smart grids and the socio-economic context. Moreover, the relevance of the proposed policies related to the development of smart grids can be seen from different perspectives, which justifies the importance of eliciting information from multiple stakeholders for decision support purposes.

The aim of this paper is to present and to assess a set of policies identified by different stakeholders as having a potential major contribution for the development of smart grids in Brazil. The methodology to shape this set of policies consisted of a thorough literature review of international experiences combined with meetings with experts in several domains (companies and entities in the electricity sector, government bodies including regulators, academia) in order to identify the current situation and development prospects of smart grids in Brazil. An assessment of these policies was made by applying a Delphi questionnaire [10][11][12] with the purpose of measuring their effectiveness in fulfilling the objectives associated with investments in smart grids.

This introduction provided the context and motivation of the study. Section 2 examines the need of public policies for the development of smart grids due to the economic characteristics of the electricity sector. In section 3, the set of public policies is presented. Section 4 provides an account of the application of the Delphi method to elicit information from stakeholders. The main results obtained are presented in section 5. Finally, some conclusions and implications are drawn in section 6.

\section{Public Policies for Smart Grids}

It has been recognized that conventional grids are not adequate to meet the demands of the electrical system in the near future due to concurrent challenges: increasing shares of distributed generation, including micro-generation at customers' premises (who become "prosumers", i.e. simultaneously producers and consumers), implementation of active demand-side management mechanisms possibly responding to dynamic price signals, deployment of storage systems including electric vehicles operation in vehicle-to-grid mode [13][14][15]. The dissemination of distributed generation based on renewable and intermittent sources may result in bidirectional energy flows in the grid and the growing share of electric vehicles imposes new technical challenges. Active demand control, storage systems and electric vehicles might increase problems in the grid. As a result, the grid requires further control and automation mechanisms, including the deployment of smart metering systems at the customers' premises. This emerging technological paradigm, in which consumers will play a more prominent role through demand response mechanisms, needs to be supported by appropriate public policies incentivizing investments on technological innovations in the grid [16][17][18][19].

The examination of the dynamics of implementation of smart grids requires the prior recognition of technical and economic characteristics of the electricity sector. Besides being an industry that requires instantaneous balance between demand and supply, other economic characteristics can be highlighted: it is a capital-intensive industry with a homogeneous product; inelastic demand; regulated (access to grid) tariffs due to the existence of natural monopolies [20][21]. These characteristics do not favor the occurrence of innovation processes endogenously to the dynamics of the sector. Innovation generally occurs because the firm obtains a new process or product that allows it to make extraordinary profits for a certain period of time [22]. Given that electricity is a homogeneous good, product differentiation is 
limited. In contrast, new technologies initially tend to have a higher cost than the conventional alternatives. As a result, the strict market conditions do not favor the diffusion of technologies, for instance those with less environmental impact [23][24].

In cases the innovation process may be hindered by the industry characteristics and/or the regulatory framework, it is appropriate to adopt public policies that are able to mitigate barriers to innovation and therefore incite innovation by economic agents. However, it is not enough to recognize the need for this intervention, being also necessary to know the typologies of policy instruments and the characteristics of those barriers to succeed [25]. It is noteworthy that this intervention by policy makers should only occur when the implementation of innovation policies is justifiable. Thus, the interaction between different interest groups and agents with government institutions is essential to the creation of networks and, consequently, a coalition of stakeholders supporting the emerging technologies [26].

The diffusion of new technologies in the electricity sector follows a dynamic that begins with the research and development activities aimed at solving technical problems and reduce costs. Considering the nature of these activities, a high level of uncertainty with regard to its results is at stake. Further, there is the demonstration stage, in which technology must prove its feasibility. Finally, there is the market development and commercial distribution stage. It is important to highlight the value of public policies throughout this process to fund both research and development activities and demonstration activities. It is also important to highlight the central role of public policies in supporting new technologies to permeate the market [27]. In this context, Kiss and Neji [28] recognize the important role of government intervention in the innovation process, whose success depends on the public policy strategies adopted. More specifically, Sung and Song [26] emphasize the central role of government in technology development in the field of renewable energy.

In the case of smart grids, the scope of research and development projects, as well as demonstration projects, is quite broad. In this sense, we note the relevance of carrying out projects related to grid automation, large-scale integration of renewable energy, electric vehicles, demand-side management and projects related to solutions like smart metering [29][30]. Considering the fact that a technological transition is a process that goes beyond the technological sphere, these projects must also include other variables, especially the issue of social acceptance [31]. For example, it is quite important to develop studies that address the price elasticity of demand in order to gauge the real impacts that demand response measures have on the system. For this purpose, Broman Toft, Schuitema and Thøgersen [32] suggest that research is needed to achieve a better understanding of what makes consumers accept or reject smart grid technologies in order to properly develop and effectively spread these new technologies and to achieve the political goals regarding the smart grid.

Given that the electricity distribution consists of a natural monopoly and it is a heavily regulated activity [3][33], the peculiarities of the market diffusion of smart grids should be emphasized. Thus, the incentives to smart grids tend to be more associated with changes in the regulatory setting than the formulation of public policies in a broader sense. In contrast to conventional grids, smart grids are characterized by a higher proportion of operating costs relative to the amount of capital invested. Therefore traditional regulatory models, which are predominantly price-based or incentive regulation, are not adequate for investments in smart grids, because they are focused on the asset base [3][34]. Thus, the economic and financial attractiveness of investments in the grid automation and the rollout of smart meters become questionable under most present regulatory frameworks.

When considering the set of technologies related to smart grids (ICT, micro-generation, storage, demandside management using smart meter data, etc.), it is noticeable that the electrical system will experience a greater participation of distributed energy resources and a more flexible demand, with consumers taking a more active role. In this way, conditioning the distributor's revenue to the energy distributed may compromise the economic viability of the utilities, showing the importance of rethinking regulation in this context. Among the issues to be discussed, it stands out the asset base remuneration, the tariff structure, the establishment of which activities remain regulated and which will be open to competition, the ownership of new devices (smart meters, charging stations for electric vehicles, big data, etc.) and the relationship between the distribution and transmission companies [35][36].

Also as part of the regulatory changes, it is worth highlighting the importance of the electric power industry interface with the telecommunications industry to the development of smart grids. Lin, Yang and Shyua [9] emphasize the need to adopt policies and regulations that remove barriers to investment in ICT 
and allow the exploitation of the full potential in the value chain as a precondition for the development of smart grids. Erlinghagen and Markard [37], in turn, consider ICT firms as potential catalysts for changes in the electricity sector.

Hence, it can be stated that the technological transition represented by smart grids is not expected to occur endogenously to the dynamics of the electricity sector. As a result, the implementation of incentive policies and changes in the regulatory framework are a necessity for the development of smart grids, as can also be seen from the international experience. The definition of those policies must consider the particularities of each country and the interests of different stakeholders.

\section{Public Policies for Smart Grids Development}

From the evidence of the need of public policies to foster the development of smart grids, the discussion about smart grids in Brazil concluded that this process requires adequate policy proposals and regulatory measures. For this purpose, based on the analysis of the current status, the prospects and the challenges of smart grids in Brazil [38], the discussion with stakeholders in several sectors and the study of the international experience of incentive policies for smart grids [9][18][39][40][41], a set of eight public policies for the development of smart grids in Brazil was defined. The proposed policies are quite varied in their contents and scope, not being mutually exclusive. The policies are briefly described in the next subsections.

\subsection{Mandatory Rollout of Smart Meters}

Considering that the real-time monitoring of all energy flows requires a smart metering system, the installation of smart meters is an important action to deal with the challenges associated with the diffusion of distributed generation (especially micro-generation), which in the future may be associated with energy storage. Furthermore, smart meters are essential for the adoption of demand-side management measures and are an enabling technology for the adoption of dynamic electricity tariff schemes. In sum, a smart metering system has the potential to endow the electrical system higher efficiency and reliability. In the context of establishing goals for the development of smart grids, the mandatory rollout of smart meters is a measure commonly verified worldwide. As an illustration, the EU Directive [42], which encourages the optimal usage of energy resources, emphasizes the importance of adopting smart metering systems. This directive makes clear that one of the goals associated with the implementation of intelligent metering systems is assisting the active participation of consumers in the electricity supply market. In the same direction, it is possible to mention the rollout of smart meters already done in California [43].

However, although the installation of smart meters has the potential to improve quality of service, operational costs and global system operation, their deployment sets out new technical, regulatory, economic and social challenges. Thereby, the interests of different stakeholders must be considered. The issue of data privacy is very controversial and in some cases there is opposition from consumers to the installation of these meters [44]. To mitigate this drawback, the Netherlands and California granted the consumer the right to refuse the installation of the smart meter [45]. At the same time, the property of big data, and the consequent possibility to exploit them commercially, is a topic still under discussion. The tendency in the European Union is to classify these big data as a public good.

The nub of the question of the viability of the rollout of smart meters is associated with the investment costs. The manner in which such costs shall be borne and the sharing of benefits among different stakeholders takes on enormous importance on decisions. As an illustration, although the European Union has set a rollout minimum target for each country ( $80 \%$ of the metering points), this target should be fulfilled only in cases where the cost-benefit analysis prove to be positive [46]. The result of the analysis varies from country to country depending on the electrical system and the market structures, or even the prospected consumers' behavior [46][47]. In Italy, for example, the rollout was implemented before any regulations about smart meters, being feasible by reducing operating costs and non-technical losses. In France, meanwhile, the ongoing rollout was deemed feasible by the expected reduction in operating costs. In Germany, however, the cost-benefit analysis indicates a negative result due to reasons such as a poor efficiency prospected for demand response measures [48].

In sum, as can be seen from the international experience, the adoption of a mandatory rollout of smart meters in Brazil is a policy that should be examined. In addition, Brazil has some specific drivers associated with the rollout of smart meters. For example, it can be mentioned the issue of combating non- 
technical losses in some regions of Brazil. Although smart meters are not able by themselves to reduce these losses, they permit to accurately identify their location and therefore support the adoption of effective measures to combat them. Other drivers of smart meter diffusion in Brazil can be cited: the adoption of dynamic electricity tariff schemes, real-time monitoring of the load and the necessity to deal with bidirectional energy flows in prosumers. The installation of these meters should be done by the distribution companies and the costs passed on to the final consumer through some tariff scheme. Considering the high number of distribution companies in Brazil, the option for a mandatory rollout, as part of a national plan for developing smart grids, is justified by the exploitation of economies of scale. On the other hand, we must emphasize that the precariousness of the Brazilian telecommunications network turns this rollout a high cost policy, given the need for investment in the telecommunications network also.

\subsection{Regulatory Changes to Foster Innovation in the Electricity Sector}

The implementation of smart grids requires substantial investments in the network, especially in distribution networks. These capital expenditures are associated with the need to replace existing assets, the deployment of new control and automation devices and the provision of information and communication infrastructure. Since electricity distribution is a regulated activity, the attractiveness of these investments is associated with the current regulatory framework [49].

In general, the current regulatory framework does not foster the prospected changes in the electricity sector. Although price-cap models are based on the logic of incentive regulation in order to encourage efficiency, in practice the remuneration on the asset base continues to be pre-defined and commonly there is no incentive to adopt more efficient technologies [39][50]. Furthermore, the choice of these new technologies may not be feasible in economic terms. This happens because, in general, the current regulatory frameworks do not stimulate the agents to choose the most efficient technology. Indeed, these frameworks do not recognize that investment and/or remunerate it properly, especially with regard to technologies characterized by a higher proportion operational expenditures (OPEX) in relation to capital expenditures (CAPEX) in their cost structure. In particular, investments in telecommunications networks and information technology may be problematic.

For this aim, regulatory changes appear to be necessary. There should be an effective transformation of the regulatory logic with the emergence of output-based models over traditional input-based models. The choice of output-based models lies on the premise that distribution companies have more capacity to scale the required investments and, therefore, it is appropriate to grant autonomy to these companies. Thus, the regulator function shall be to establish minimum requirements for reliability and quality of service to be met by distribution companies. Companies are encouraged to make investments considering that the regulator establishes criteria for incentives and penalties. It can be concluded that these models create conditions for effective renewal and modernization of assets [39][50]. Nevertheless, it should be noted the importance of developing methodologies to remunerate properly technologies with a higher proportion of OPEX in their cost structure.

As an illustration of possible regulatory developments, recent changes in UK regulation with the introduction of RIIO framework (Revenue = Incentives + Innovation + Outputs) are quite representative. In RIIO, taking into account the need to provide the British electricity sector greater sustainability, the regulator (OFGEM) reshaped the current price-cap model by inserting elements that induce innovation [40]. Given that this is an output-based incentive scheme, the RIIO framework not only gives to the British utilities the investment decisions, but also provides incentives for companies to opt for more efficient technologies and, at the same time, implement innovations.

Therefore, in order to develop smart grids through the modernization of the Brazilian networks, the adoption of a regulatory model based on incentives is recommended. Thus, the distribution companies, even if subjected to targets, will have autonomy to decide which investments they should carry out, so that more efficient technologies can be adopted.

Finally, given that the transformation prospected for the electricity sector also includes the diffusion of distributed energy resources (micro-generation, demand response, storage, electric vehicles) and the increasing power generation from intermittent renewable sources, it is required that the regulatory changes deal with even broader matters. For this purpose, it becomes still more important the adoption of decoupling mechanisms that mitigate the natural tendency of the distribution companies in opposing technologies/measures that reduce their market. Concomitantly, it is essential the introduction of tariff 
structures that allocate properly the costs between different users. Moreover, tariffs should have a dynamic time-of-use component aiming to reflect the market and grid conditions.

\subsection{Improvement of Research \& Development and Demonstration Projects}

Although there are some Research \& Development (R\&D) and demonstration projects focused on smart grids in Brazil, there is a strong dependence on the financial resources of the R\&D program of the regulator of the electrical energy sector (ANEEL) and, to some extent, of Inova Energy Program [51]. As a result, the coverage and dissemination of projects tends to be more limited. Meanwhile, there is a reduced involvement of industry in the technological development process. Thus, there is evidence that the $R \& D$ projects are not being sufficiently able to encourage the creation and diffusion of technological innovations. In this context, there is need of a greater coordination/integration of different projects and industry involvement in these, with an emphasis on projects with higher levels of technological maturity. Furthermore, it is appropriate to build a shared knowledge base that enables a more forceful diffusion of project results.

As an illustration of the importance of implementing projects with higher levels of technological maturity, in the European Union there is greater investment in smart grid demonstration projects than in $R \& D$ projects. This shows the importance of smart grid projects not remaining restricted to the pilot/experimental stage, but effectively acting as inducers of investments in grid modernization through the adoption of technological innovations [52].

At the same time, it is noteworthy the importance of having incentives for adopting projects with higher levels of risk. For this aim, the adoption of a risk premium on the rate of return of such projects is a relevant strategy [49]. This type of guideline has been adopted in some countries; for example, in Italy the regulation enables pilot projects earn a $2 \%$ risk premium over 12 years [40].

Additionally, it is possible to discuss the relevance of the use of the ANEEL's energy efficiency program funds for smart grid projects and that the available resources can also be used in applied projects. Such strategy has the objective of encouraging the effective implementation of technological innovations in the electricity sector. More specifically, the success of the pilot projects is not sufficient, being also necessary to create conditions for the diffusion of new systems and equipment. Finally, it is desirable that the projects include the qualification of specialized workforce.

\subsection{Incentive Policies for Promoting Demand-Side Management, Distributed Generation and Storage}

Although this article focuses on smart grids in a strict sense (smart metering systems and grid automation), there are some related technologies/measures that represent a new technological paradigm [2]. This is characterized by the emergence of an electrical system consisting of distributed energy resources where consumers have more active behavior and adopt demand-side management measures. The adoption of policies promoting the diffusion of these technologies/measures, as well as regulatory guidelines for this purpose, is expectedly capable of inducing the development of smart grids.

In this regard, it is noticed that the establishment of dynamic time-of-use tariffs is a key element for the realization of investment in the rollout of smart meters [53]. One of the main benefits of the deployment of smart meters is the possibility of managing demand, especially in the context of demand response programs, which are generally associated with signals conveyed by dynamic pricing models.

Although the investment in micro-generation units does not depend on the existence of a smart grid, the effective diffusion of a system characterized by the massive presence of distributed energy resources, while guaranteeing the reliability and quality of the power supply, requires the implementation of smart grids able to perform a real-time monitoring of all electricity flows [54]. The significant presence of intermittent generation sources in the generation matrix emphasizes the need of implementing demandside management measures, in a context of a paradigm shift from "supply follows load" to "load follows supply" strategies [55].

Therefore, the establishment of incentive policies and guidelines aimed at the diffusion of these technologies leads to the development of smart grids. Such policies have already been established worldwide, especially in developed countries [56][57]. For instance, the feed-in tariffs implemented in several EU member countries have the aim of encouraging investment in micro-generation. In Brazil there are also steps in this direction, such as ANEEL's Normative Resolution No. 482 [58][59], which 
deals with the regulation of micro- and mini-generation. In any case, tax exemptions and special lines of credit are important tools for advances in incentive policies for distributed energy resources.

It is noteworthy that, in contrast to micro-generation, there is still a degree of uncertainty about the prospects for the diffusion of storage technologies at the consumer level. Therefore, incentive policies assume greater importance. Attention is paid to electric vehicles, which possibly represent the most immediate option for energy storage through the operation of its battery in vehicle-to-grid (V2G) mode. However, despite the relevance of the adoption of incentive policies for distributed energy resources, it is worth noting that it must be accompanied by changes in the regulatory framework in the distribution segment, given the need to ensure that the diffusion of these technologies does not compromise the economic/financial viability of electricity distribution companies.

\subsection{Establishing Quality Standards for the Telecommunications Industry}

Given that smart grids rely heavily on ICT, the telecommunications network quality has a large importance for their development. In short, a reliable telecommunications network is required for the effective implementation of smart grids [60].

The Brazilian telecommunication network is precarious. Given that hiring telecom operators to provide services has been an ineffective solution, since the service has a lower performance than required, the electricity distribution companies have been opting for constructing their own telecommunication networks in their projects. The issue is that adopting this strategy entails a significant increase in costs for the smart grid projects, considering that these investments may represent between $21 \%$ and $36 \%$ of total spending [61].

For this purpose, a better regulation of the relations between the electricity and the telecommunications sectors is necessary. The availability of an efficient telecommunications network would eliminate the need to carry out substantial investments in the implementation of own networks. Furthermore, it is noteworthy that telecommunication networks belonging to the distribution companies tend to be idle due to the impossibility of electricity companies to exploit telecommunication services. On the other hand, meeting the telecommunications needs for smart grids is a business opportunity for telecommunication companies.

Therefore, considering that the establishment of quality standards for telecommunications operators would help reducing the need for investment by the electricity companies, it is necessary to examine in greater detail the adoption of this policy. This policy is especially important since it makes the rollout of smart meters by the electricity distribution companies more feasible, due to the lower expenditure required for the implementation of smart metering systems.

\subsection{Regulation of New Business Models}

As pointed out by [62], the prospected changes for the electricity sector are not consistent with the traditional utility business model. Besides the changes in the regulatory framework of regulated activities to ensure the economic and financial feasibility of electric utilities, it is necessary to regulate new business models. In general, the emergence of a paradigm characterized by the presence of distributed energy resources, where all energy flows are monitored in real time, leads to new business opportunities to be exploited. These opportunities range from new products and systems to the exploration of solutions and services. It is also necessary to regulate the activities of new agents, such as the entry of startups in the sector. At the same time, issues related to the participation of distribution companies in unregulated activities should be addressed.

The importance of new business models stems from the observation that the creation of value for consumers, and the consequent profit taking by entrepreneurs, is essential for the transition to smart and sustainable electrical systems. Therefore, it is not enough to know the technical characteristics of smart grids and related technologies; attention should also be paid to the concerns of firms and consumers when transacting goods and services related to smart grids [63].

From the perspective of the companies in the electricity sector, the consequences of the expansion of smart grids and distributed energy resources are ambiguous, since it may be harmful to the traditional business model and at the same time may provide new business opportunities. On the one hand, the prospects of market reduction and entry of new agents constitute a threat for traditional firms in the electricity sector. At the same time, distribution companies may incur additional costs arising from new 
technologies. On the other hand, in addition to the possibility of reducing system costs due to efficiency gains, new opportunities arise, for example the integration of renewable resources, demand response programs, vehicle-to-grid operation and the exploitation of big data [64].

For this aim, it is possible to foresee the appearance of new agents such as load aggregators and virtual power plants, as well as a more active role of energy efficiency service providers. The volume of available data will allow the design of services personalized to the needs of each consumer. The emergence of new agents and the permission for distribution companies to act in unregulated markets are trends already observed in countries where the electricity sector transformations are ongoing. In short, the main issue is the creation of a regulatory framework that allows and incites the use of business models compatible with the emerging new technological paradigm.

\subsection{Development Plan for Smart Cities}

In accordance with the need to meet the contemporary socio-economic demands without imposing major impacts on the environment, the concept of smart cities is gaining relevance. According to Calvillo et al. [65], smart cities can be defined as sustainable and efficient urban centers providing a high quality of life to their inhabitants through optimal integrated management of resources. Given the complexity and the importance of energy systems, the discussion about smart cities is associated with the search for efficient and sustainable energy solutions. As a result, it is apparent that the development of smart grids consists of a prerequisite for the development of smart cities.

However, since the concept of smart cities promotes the rational, integrated and sustainable use of all resources, there is an evident need to adopt new paradigms in other infrastructure industries (water, sanitation, urban transport, telecommunications, etc.), which should also become smart(er) through the ubiquitous use of ICT [66]. Therefore, the relevance of sharing the communication infrastructures is a relevant issue.

In this context, the establishment of development plans for smart cities is a strategy with potential to incite investments in smart grids, not just because smart grids are essential to smart cities but also to enable the sharing of ICT infrastructures with other public service operators, thus reducing the investment cost required. In addition, these development plans will allow taking advantage of synergies between different services, for example, enhancing the combination of energy efficiency programs with stimulus plans to electric mobility in urban transportation.

\subsection{National Development Policy for Smart Grid Industry}

The development of smart grids has the ability to provide economic benefits to the country provided domestic industry is capacitated so that it is able to supply the domestic market. Under this strategy, the export of goods and services should also be considered and technology export is an important driver for the development of smart grids, as can be seen in countries such as Germany and South Korea [67][68].

For this purpose, a set of financial incentives to the industrial development could be adopted, which would be gradually reduced with the level of industrial development attained. At the same time, it is worth highlighting the importance of attractive financing conditions for investments in industrial equipment plants. In addition to financial incentives, it is also desirable to establish rules that encourage a higher level of R\&D activity throughout the whole supply chain. These incentives should be focused on market niches where the country has greater endogenous capacities/potentialities.

Another important initiative in this setting is the establishment of partnerships with countries in more advanced stages in the development of smart grids. These agreements aim to exchange experiences and the trade of technologies already tested and approved worldwide. It should be noted that this technology transfer may be conditional upon the adaptation of such technology to Brazilian specificities. It is also extremely important to establish trade agreements that allow Brazil to export equipment to markets in which it has competitive advantages, as well as the import of equipment that the domestic industry is not able to provide. In this context, it is important to establish norms, standards and interoperability compatible with the best international practices in order to enable Brazilian companies to compete in international markets. 


\section{Methodology for Evaluating Proposed Policies}

In order to examine the proposed public policies a Delphi questionnaire was designed, which was applied to a selected group of experts and stakeholders in the electricity sector. The purpose of this section is to review the Delphi approach and describe the survey.

\subsection{The Delphi Method}

The main objective of the Delphi methodology in the framework of this study was to obtain the most reliable consensus of opinion by the group of experts and stakeholders. The method was applied through an iterative questionnaire, formulated by the coordinating team, applied in consecutive rounds until a satisfactory degree of consensus among respondents was obtained. This consensus represents a consolidation of the intuitive judgment of the group of experts [12]. As pointed out by some authors [11][10], three features that eliminate the negative effects of group interactions and characterize the Delphi method are: respondents are anonymous to each other, statistical representation of the results, and feedback after each round to revaluation of experts.

Based on the literature review and interviews with industry experts, the coordinating research team designed the questionnaire. After designing the questionnaire, a group of experts qualified to answer the questions was selected. A major concern was that this group should have a balanced and representative distribution of the electricity sector, i.e., universities, government institutions and industry representatives.

After the return of the first round responses from experts, the research team analyzed the results and derived some descriptive statistics (mean, quartiles and standard deviation). Part of this information was then provided in the second questionnaire. Thus, each expert had the opportunity to review his answers against the group's tendency [12]. Although new rounds could have taken place until a satisfactory degree of consensus had been reached, the second questionnaire already displayed this characteristic. Goluchowicz and Blind (2011) argue, based on empirical studies, that the stronger convergences occur between the first and the second round.

\subsection{Application of the Delphi Method}

The first phase of the research comprised the identification of invited experts and the preparation of questionnaire 1. Regarding the choice of the participants, a set of 64 relevant experts in the electricity sector was identified, for which invitations were sent. At this stage, a major concern was diversifying the experts, extending the invitation to the areas of knowledge (academia and consulting), electricity companies and government. From the total of 64 experts invited, 35 responded to the first questionnaire and 28 responded to the second questionnaire.

Regarding the formulation of the questions contained in the questionnaire, the aim was to cover a comprehensive range of issues associated with the development of smart grids. Due to the wide variety of these issues, a prior structuring was necessary to facilitate the assessment of potential incentive policies. For this purpose, from a set of issues originally listed as potential concerns and criteria for evaluation, a categorization was held aiming to propose a set of seven fundamental objectives in line with priorities for technological innovation in the energy sector: i) benefit the environment and human health; ii) enhance flexibility and capabilities of the system technological infrastructure; iii) ensure security of supply; iv) ensure openness, fairness, transparency and efficiency of markets; v) provide financial benefit to the agents involved; vi) provide economic and social benefit to the country; vii) ensure feasibility and promote the adoption of technological innovations.

From the seven fundamental objectives identified, eight questions were formulated. Questions 1 to 7 intended to collect the perceptions of the experts about the impact that each policy would have taking into account the objectives, in a range from -5 to +5 . Figure 1 (Appendix A) exemplifies how the question \#1 of the first questionnaire was shown to participants. Questions 2 to 7 have the same structure of the first question, only varying the objectives considered in the assessment. Question \#8 intended to elicit the perspective of the experts on the relative importance of each objective in a range from 0 to +5 (Figure 2, Appendix A).

The questionnaire 2, due to the nature of the Delphi method, included some statistical information on the results obtained in the questionnaire 1 . The research team chose to provide in each question the arithmetic 
mean and the standard deviation of the answers to questionnaire 1 , as well as a chart summarizing this information. Figure 3 (Appendix A) illustrates how this procedure was performed.

After the return of the second questionnaire, the research team concluded that the answers contemplated a satisfactory degree of convergence and consensus, thus making a possible third round unnecessary. The presentation and analysis of results is made in section 5 .

\section{Results and Discussion}

This section presents the results of the Delphi method. Each subsection refers specifically to a question of the questionnaire, presenting the question asked and the results of the first and the second rounds of the Delphi method. For this purpose, a table with the standard deviation (SD1 e SD2) and the arithmetic mean (AM1 and AM2) of each round are presented, besides a ranking of the proposed policies considering the objective addressed in the question. In question 8 , a table with the same information is provided, but with the ranking of the objectives. This ranking is based on the arithmetic mean (average score) obtained by the answers of the experts after the end of the second round of the questionnaire.

Table 1. Question \#1: Policies and Objective of "Benefit the Environment and Human Health"

\begin{tabular}{|l|c|c|c|c|c|}
\hline \multicolumn{1}{|c|}{ Public Policies } & SD1 & AM1 & SD2 & AM2 & Ranking \\
\hline 1- Mandatory Rollout of Smart Meters & 1.87 & 1.53 & 1.42 & 1.39 & 8 th \\
\hline 2- Regulatory Changes to Foster Innovation in the Energy Sector & 1.56 & 3.03 & 1.2 & 2.96 & 4 th \\
\hline $\begin{array}{l}\text { 3- Improvement of Research \& Development and Demonstration } \\
\text { Projects }\end{array}$ & 1.52 & 2.62 & 1.38 & 2.71 & 6 th \\
\hline $\begin{array}{l}\text { 4 - Incentive Policies for Promoting Demand-Side Management, } \\
\text { Distributed Generation and Storage }\end{array}$ & 1.56 & 3.54 & 1.15 & 3.86 & $1 \mathrm{st}$ \\
\hline $\begin{array}{l}\text { 5 - Establishing Quality Standards for the Telecommunications } \\
\text { Industry }\end{array}$ & 1.78 & 2.5 & 1.8 & 2.19 & 7 th \\
\hline 6- Regulation of New Business Models & 1.77 & 2.68 & 1.55 & 2.75 & 5 th \\
\hline 7 - Development Plan for Smart Cities & 1.41 & 3.8 & 1.52 & 3.79 & $2 \mathrm{nd}$ \\
\hline \begin{tabular}{l} 
8- National Development Policy for Smart Grid Industry \\
\hline
\end{tabular}
\end{tabular}

Table 2. Question \#2: Policies and Objective of "Enhance Flexibility and Capabilities of the System Technological Infrastructure"

\begin{tabular}{|l|c|c|c|c|c|}
\hline \multicolumn{1}{|c|}{ Public Policies } & SD1 & AM1 & SD2 & AM2 & Ranking \\
\hline 1 - Mandatory Rollout of Smart Meters & 1.46 & 3.6 & 1.08 & 3.37 & 7th \\
\hline 2- Regulatory Changes to Foster Innovation in the Energy Sector & 1.24 & 3.86 & 0.71 & 4.04 & 1 st \\
\hline $\begin{array}{l}\text { 3 - Improvement of Research \& Development and Demonstration } \\
\text { Projects }\end{array}$ & 1.17 & 3.63 & 0.98 & 3.48 & 6 th \\
\hline $\begin{array}{l}\text { 4 - Incentive Policies for Promoting Demand-Side Management, } \\
\text { Distributed Generation and Storage }\end{array}$ & 1.44 & 3.63 & 0.74 & 3.81 & 2nd \\
\hline $\begin{array}{l}\text { 5 - Establishing Quality Standards for the Telecommunications } \\
\text { Industry }\end{array}$ & 1.53 & 3.12 & 1.35 & 2.85 & 8th \\
\hline 6- Regulation of New Business Models & 1.24 & 3.6 & 0.97 & 3.78 & 3rd \\
\hline 7- Development Plan for Smart Cities & 1.2 & 3.68 & 1.1 & 3.74 & 4th \\
\hline 8- National Development Policy for Smart Grid Industry & 1.45 & 3.66 & 0.93 & 3.63 & 5th \\
\hline
\end{tabular}


Table 3. Question \#3: Policies and Objective of "Ensure Security of Supply"

\begin{tabular}{|l|c|c|c|c|c|}
\hline \multicolumn{1}{|c|}{ Public Policies } & SD1 & AM1 & SD2 & AM2 & Ranking \\
\hline 1- Mandatory Rollout of Smart Meters & 1.59 & 2.35 & 1.15 & 2.14 & 7 th \\
\hline 2- Regulatory Changes to Foster Innovation in the Energy Sector & 1.34 & 3.29 & 0.90 & 3.29 & $2 \mathrm{nd}$ \\
\hline $\begin{array}{l}\text { 3- Improvement of Research \& Development and Demonstration } \\
\text { Projects }\end{array}$ & 1.58 & 3.03 & 1.23 & 2.96 & 5 th \\
\hline $\begin{array}{l}\text { 4- Incentive Policies for Promoting Demand-Side Management, } \\
\text { Distributed Generation and Storage }\end{array}$ & 1.44 & 3.83 & 0.94 & 4.07 & $1 \mathrm{st}$ \\
\hline $\begin{array}{l}\text { 5 - Establishing Quality Standards for the Telecommunications } \\
\text { Industry }\end{array}$ & 1.55 & 2.72 & 1.32 & 2.04 & 8 th \\
\hline 6- Regulation of New Business Models & 1.62 & 2.97 & 1.27 & 2.75 & 6 th \\
\hline 7 - Development Plan for Smart Cities & 1.51 & 3.06 & 1.37 & 3.11 & 3rd \\
\hline 8- National Development Policy for Smart Grid Industry & 1.58 & 3.09 & 1.23 & 3.11 & 4th \\
\hline
\end{tabular}

Table 4. Question \#4: Policies and Objective of "Ensure Openness, Fairness, Transparency and Efficiency of Markets"

\begin{tabular}{|l|c|c|c|c|c|}
\hline \multicolumn{1}{|c|}{ Public Policies } & SD1 & AM1 & SD2 & AM2 & Ranking \\
\hline 1- Mandatory Rollout of Smart Meters & 1.78 & 2.71 & 1.25 & 2.56 & 7 th \\
\hline 2- Regulatory Changes to Foster Innovation in the Energy Sector & 1.36 & 3.49 & 0.88 & 3.57 & 3 rd \\
\hline $\begin{array}{l}\text { 3- Improvement of Research \& Development and Demonstration } \\
\text { Projects }\end{array}$ & 1.49 & 2.88 & 1.28 & 2.64 & 6 th \\
\hline $\begin{array}{l}\text { 4- Incentive Policies for Promoting Demand-Side Management, } \\
\text { Distributed Generation and Storage }\end{array}$ & 1.36 & 3.49 & 0.93 & 3.86 & 1 st \\
\hline $\begin{array}{l}\text { 5 - Establishing Quality Standards for the Telecommunications } \\
\text { Industry }\end{array}$ & 1.77 & 2.52 & 1.49 & 2.15 & 8 th \\
\hline 6- Regulation of New Business Models & 1.54 & 3.54 & 1.05 & 3.71 & $2 \mathrm{nd}$ \\
\hline 7 - Development Plan for Smart Cities & 1.57 & 2.69 & 1.15 & 3.00 & 5 th \\
\hline 8- National Development Policy for Smart Grid Industry & 1.36 & 2.91 & 1.12 & 3.07 & 4 th \\
\hline
\end{tabular}

Table 5. Question \#5: Policies and Objective of "Provide Financial Benefit to the Agents Involved"

\begin{tabular}{|l|c|c|c|c|c|}
\hline \multicolumn{1}{|c|}{ Public Policies } & SD1 & AM1 & SD2 & AM2 & Ranking \\
\hline 1- Mandatory Rollout of Smart Meters & 2.53 & 2.21 & 1.92 & 2.37 & 7 th \\
\hline 2- Regulatory Changes to Foster Innovation in the Energy Sector & 1.6 & 2.97 & 0.93 & 3.25 & 3 rd \\
\hline $\begin{array}{l}\text { 3- Improvement of Research \& Development and Demonstration } \\
\text { Projects }\end{array}$ & 1.44 & 2.73 & 1.17 & 2.54 & 6 th \\
\hline $\begin{array}{l}\text { 4- Incentive Policies for Promoting Demand-Side Management, } \\
\text { Distributed Generation and Storage }\end{array}$ & 2.14 & 3.12 & 1.24 & 3.25 & 4 th \\
\hline $\begin{array}{l}\text { 5 - Establishing Quality Standards for the Telecommunications } \\
\text { Industry }\end{array}$ & 2.00 & 1.85 & 1.37 & 1.59 & 8 th \\
\hline 6- Regulation of New Business Models & 1.5 & 3.47 & 0.77 & 3.93 & 1 st \\
\hline $\begin{array}{l}\text { 7 - Development Plan for Smart Cities } \\
\text { 8- National Development Policy for Smart Grid Industry }\end{array}$ & 1.74 & 2.65 & 1.25 & 2.93 & 5 th \\
\hline
\end{tabular}


Table 6. Question \#6: Policies and Objective of "Provide Economic and Social Benefit to the Country"

\begin{tabular}{|l|c|c|c|c|c|}
\hline \multicolumn{1}{|c|}{ Public Policies } & SD1 & AM1 & SD2 & AM2 & Ranking \\
\hline 1- Mandatory Rollout of Smart Meters & 2.4 & 2.31 & 1.67 & 2.22 & 8 th \\
\hline 2- Regulatory Changes to Foster Innovation in the Energy Sector & 1.31 & 3.74 & 1.00 & 3.75 & 4 th \\
\hline $\begin{array}{l}\text { 3- Improvement of Research \& Development and Demonstration } \\
\text { Projects }\end{array}$ & 1.40 & 3.54 & 1.26 & 3.46 & 6 th \\
\hline $\begin{array}{l}\text { 4 - Incentive Policies for Promoting Demand-Side Management, } \\
\text { Distributed Generation and Storage }\end{array}$ & 1.25 & 4.09 & 0.89 & 4.14 & $1 \mathrm{st}$ \\
\hline $\begin{array}{l}\text { 5 - Establishing Quality Standards for the Telecommunications } \\
\text { Industry }\end{array}$ & 1.73 & 3.15 & 1.67 & 2.63 & 7 th \\
\hline 6- Regulation of New Business Models & 1.43 & 3.69 & 0.88 & 3.79 & $3 \mathrm{rd}$ \\
\hline 7 - Development Plan for Smart Cities & 1.38 & 3.74 & 1.08 & 3.71 & 5 th \\
\hline 8- National Development Policy for Smart Grid Industry & 1.38 & 3.83 & 1.03 & 3.89 & $2 \mathrm{nd}$ \\
\hline
\end{tabular}

Table 7. Question \#7: Policies and Objective of "Ensure Feasibility and Promote the Adoption of Technological Innovations"

\begin{tabular}{|l|c|c|c|c|c|}
\hline \multicolumn{1}{|c|}{ Public Policies } & SD1 & AM1 & SD2 & AM2 & Ranking \\
\hline 1- Mandatory Rollout of Smart Meters & 2.05 & 2.44 & 1.55 & 2.22 & 8 th \\
\hline 2- Regulatory Changes to Foster Innovation in the Energy Sector & 1.07 & 4.21 & 0.63 & 4.43 & 1 st \\
\hline $\begin{array}{l}\text { 3- Improvement of Research \& Development and Demonstration } \\
\text { Projects }\end{array}$ & 1.23 & 4.12 & 1.15 & 4.07 & $2 \mathrm{nd}$ \\
\hline $\begin{array}{l}\text { 4- Incentive Policies for Promoting Demand-Side Management, } \\
\text { Distributed Generation and Storage }\end{array}$ & 1.42 & 3.47 & 1.04 & 3.75 & 6 th \\
\hline $\begin{array}{l}\text { 5 - Establishing Quality Standards for the Telecommunications } \\
\text { Industry }\end{array}$ & 1.71 & 3.16 & 1.50 & 2.62 & 7 th \\
\hline 6- Regulation of New Business Models & 1.27 & 3.82 & 0.88 & 4.04 & $3 \mathrm{rd}$ \\
\hline $\begin{array}{l}\text { 7 - Development Plan for Smart Cities } \\
\text { 8- National Development Policy for Smart Grid Industry }\end{array}$ & 1.28 & 3.62 & 1.15 & 3.86 & 4 th \\
\hline
\end{tabular}

Table 8. Question \#8: Relative Importance of the Objectives

\begin{tabular}{|l|c|c|c|c|c|}
\hline \multicolumn{1}{|c|}{ Objectives } & SD1 & AM1 & SD2 & AM2 & Ranking \\
\hline Objective 1: benefit the environment and human health & 1.29 & 3.74 & 1.14 & 3.54 & 7 th \\
\hline $\begin{array}{l}\text { Objective 2: enhance flexibility and capabilities of the system } \\
\text { technological infrastructure }\end{array}$ & 0.89 & 4.03 & 0.71 & 4.14 & 3 rd \\
\hline Objective 3: ensure security of supply & 0.96 & 4.2 & 0.90 & 4.18 & $2 \mathrm{nd}$ \\
\hline $\begin{array}{l}\text { Objective 4: ensure openness, fairness, transparency and } \\
\text { efficiency of markets }\end{array}$ & 0.88 & 3.77 & 0.74 & 4.04 & 5 th \\
\hline Objective 5: provide financial benefit to the agents involved & 0.97 & 3.37 & 0.80 & 3.75 & 6 th \\
\hline Objective 6: provide economic and social benefit to the country & 0.85 & 4.43 & 0.83 & 4.61 & $1 \mathrm{st}$ \\
\hline $\begin{array}{l}\text { Objective 7: ensure feasibility and promote the adoption of } \\
\text { technological innovations }\end{array}$ & 0.76 & 3.89 & 0.80 & 4.14 & 4 th \\
\hline
\end{tabular}


Starting from a more specific analysis of the results obtained by the application of the Delphi questionnaire, it is possible to identify some policies that stand out in relation to the others. For example, the "Incentive Policies for Promoting Demand-Side Management, Distributed Generation and Storage" policy obtained the best rank in four of the objectives, as well as the second rank in another objective. It is noteworthy, however, that this policy had its worst rank, in the sixth place, in the objective "Ensure Feasibility and Promote the Adoption of Technological Innovations". Seeking to understand the reasons behind this result, information was disaggregated by type of stakeholders. However, this disaggregated assessment was not able to point out major differences between the responses of the different stakeholders. We believe this was an above-average assessment of other policies regarding this objective.

Another policy that stands out for its good performance under all objectives is the "Regulatory Changes to Foster Innovation in the Energy Sector" policy. This policy did not get any result below the fourth rank. This result is very significant in respect to its implementation, i.e., this policy will hardly have major barriers to its adoption. In this sense, it is possible to suppose that the "Incentive Policies for Promoting Demand-Side Management, Distributed Generation and Storage" policy, although being the best evaluated in most of the objectives, may find some difficulty in its adoption, taking into account its poor performance in relation to the "Ensure Feasibility and Promote the Adoption of Technological Innovations" objective.

Similarly, it is possible to identify the policies that presented the worst performance. The results are quite clear in pointing out that the "Mandatory Rollout of Smart Meters" and "Establishing Quality Standards for the Telecommunications Industry" policies have obtained the worst ratings. This result is particularly relevant, and somewhat surprising, given that rollout of smart meters is one of the most widespread policies internationally. One possible interpretation of this result is the perception that the rollout of smart meters is only pertinent in a context where dynamic electricity tariff schemes are established. In this sense, the adoption of regulatory changes becomes a priority in relation to the rollout of smart meters. The classification of "Establishing Quality Standards for the Telecommunications Industry" policy is also relevant, especially considering the precariousness of the Brazilian telecommunications network. This means that the electricity distribution companies have to construct their own telecommunication networks, entailing a significant increase in costs for their smart grid projects.

The policy of "Establishing Quality Standards for the Telecommunications Industry" obtained the lowest degree of consensus. For all objectives, this policy had the highest or second highest standard deviation after the second round of the Delphi questionnaire. The reason for such a divergence can be found by evaluating the data in a disaggregated form by group of stakeholders. There was a remarkable divergence between the areas of knowledge group of respondents and electricity companies. Under all objectives, the knowledge group presented average scores significantly higher than that found for the electricity companies group. Thus, there may be some resistance from the electricity companies regarding the adoption of this policy.

There is, however, a set of policies that is not classified as positive or negative in a very apparent manner: "Improvement of Research \& Development and Demonstration Projects", "Regulation of New Business Models", "Development Plan for Smart Cities" and "National Development Policy for Smart Grid Industry". However, it is possible to highlight some interesting results regarding these policies. Firstly, it should be noted that the policies of "Development Plan for Smart Cities" and "National Development Policy for Smart Grid Industry" did not rank below the fifth position, i.e., they were not poorly evaluated under any objective. This gives them a good acceptance for its adoption, that is, there is no obvious barrier to their implementations.

The policy of "Regulation of New Business Models", in turn, presented good rankings in most of the objectives. However, two observations deserve to be highlighted. First, with a fairly high degree of consensus, this policy was ranked as the most recommended under the objective of "Provide Financial Benefit to the Agents Involved". This result seems quite consistent, given that the entry of new business models will most likely bring benefits to the agents involved. Second, the objective that gave the worst rating for this policy was to "Ensure Security of Supply", in sixth place. Thus, it is expected that the regulation of new business models does not help in a decisive way to ensure the security of supply.

Among the four policies that did not present markedly positive or negative position, it is possible to point out the policy of "Improvement of Research and Development and Demonstration Projects" as the least recommended, since it was ranked in sixth place in five of the seven objectives. It is worth noting, 
however, that this policy presented a very satisfactory result for the objective of "Ensure Feasibility and Promote the Adoption of Technological Innovations", for which it is placed in second position. This result can be explained mainly by the evaluation of the knowledge and electricity companies groups that presented average scores significantly higher than the government group. It is therefore inferred that, for knowledge and electricity company groups, $R \& D$ projects assume greater importance than for the government group.

More broadly, some interesting results can be presented. First, it is important to note that no policy presented a negative average score under any evaluation criteria. This implies that all policies are classified as beneficial to the system and, in some way, deserve to be implemented. It should be noted, however, that there are policies more recommendable than others, as already discussed. Although there are no policies that are classified as not recommended, when considering the averages after the second round of Delphi, it should be noted that some policies had negative individual assessments by some experts. These are the "Mandatory Rollout of Smart Meters" and "Establishing Quality Standards for the Telecommunications Industry" policies. This means that these policies may face some resistance to their application. Second, it is worth highlighting that the best classified policies, "Regulatory Changes to Foster Innovation in the Energy Sector" and "Ensure Feasibility and Promote the Adoption of Technological Innovations", obtained very expressive degrees of consensus for all evaluation criteria.

The question \#8 asked the experts their views on the relative importance of each objective addressed in previous questions. In this respect, the result of the Delphi questionnaire indicated forcefully that the objective with the highest importance was "Provide Economic and Social Benefit to the Country". In this sense, it must be emphasized that the policy with the best classification under this objective was "Incentive Policies for Promoting Demand-Side Management, Distributed Generation and Storage", while the worst was "Mandatory Rollout of Smart Meters". The objective with the second highest degree of importance was "Ensure Security of Supply". However, only 0.14 separate this objective, the second ranked one, from the fifth. Meanwhile, the objectives with the worst and the second worst rankings were "Benefit the Environment and Human Health" and "Provide Financial Benefit to the Agents Involved". The main implication of question \# 8 is the possibility of using such information as parameters for more sophisticated multi-criteria decision analysis methods.

\section{6 - Conclusions and policy implications}

A first and important conclusion of the assessment of public policies under analysis is that all obtained a positive average score in all questions, i.e., all policies were assessed as being positive for all objectives. This means that the experts classified all policies as good policies to be adopted, differing only in the priority that each policy should be assigned. Although there are no policies that are classified as not recommended, when considering the average scores after the second round of Delphi, it should be noted that some policies had negative individual assessments by some experts. The main implication of this finding is the fact that these assessments can act as barriers to be overcome for the adoption of these policies.

Although all policies have been evaluated as positive to contribute to technological innovations in distribution networks, it is clear that some policies have been considered more relevant than others, which may induce some form of priority in the implementation. Only three policies were ranked among the top three positions in at least five of the seven objectives. These policies were "Incentive Policies for Promoting Demand-Side Management, Distributed Generation and Storage", "Regulatory Changes to Foster Innovation in the Energy Sector" and "Regulation of New Business Models". Among the policies with the worst average scores, "Mandatory Rollout of Smart Meters" and "Establishing Quality Standards for the Telecommunications Industry" had always been the two lower-ranked policies, i.e., they were assigned lower priority under all objectives.

Considering the information in a disaggregated way, that is, from the perspective of each group of stakeholders, it is possible to identify how each group evaluated the policies. The results of the Delphi questionnaire revealed that the knowledge group was the one presenting the highest evaluations for all policies, except for the policy of "Incentive Policies for Promoting Demand-Side Management, Distributed Generation and Storage" in which it obtained the second highest position. For this policy, the government group was the one who most supported it. In addition, for the other policies, the government group had the second highest average, except for the "Smart Meters Roll Out Mandatory" policy, 
obtaining the lowest average score. It is inferred from these results that, in general, the knowledge group is the one that most supports the policies, while the government group is the second one. Thus, the effort to implement the assessed policies should take into account, above all, the willingness of electricity companies for their adoption. This group assigned the lowest average score for five of the seven policies assessed.

It is important to emphasize that policies were assessed considering distinct objectives and each question addressed these objectives separately. Attention is drawn to the fact that for every objective a distinct final classification was obtained. Thus, in order to conduct a global assessment of the public policies, i.e. evaluating the policies on the multiple objectives simultaneously, the adoption of other methodologies is required, such as multi-criteria decision analysis/aid (MCDA) methods [69]. These methods are able to consider the relative importance of objectives according to meaningful information elicited from decision makers, as well as other preference information parameters to derive recommendations according to the selection, ranking or sorting perspectives.

\section{Acknowledgements}

This work has been supported by EDP (Bandeirante Energia and Espírito Santo Centrais Elétricas) project "Evaluation of policies and incentive actions for technological innovations in the electricity sector: analysis of the international experience and proposals for Brazil" part of the R\&D Program regulated by ANEEL, Brazil. The third and fourth authors also acknowledge the support of the Portuguese Foundation for Science and Technology under project UID/MULTI/00308/2013. The authors are grateful to the experts who participated in the Delphi survey.

\section{References}

[1] Bari A, Jiang J, Saad W, Jaekel A. Challenges in the smart grid applications: An overview. Int J Distrib Sens Networks 2014;2014:11. doi:10.1155/2014/974682.

[2] Poudineh R, Jamasb T. Distributed generation, storage, demand response and energy efficiency as alternatives to grid capacity enhancement. Energy Policy 2014;67:222-31. doi:10.1016/j.enpol.2013.11.073.

[3] Joskow PL. Incentive Regulation and Its Application to Electricity Networks. Rev Netw Econ 2008;7:547-60.

[4] Pérez-Arriaga I. Regulatory instruments for deployment of clean energy technologies. San Domenico Di Fiesole: 2010.

[5] Lo Schiavo L, Delfanti M, Fumagalli E, Olivieri V. Changing the regulation for regulating the change : Innovation-driven regulatory developments for smart grids, smart metering and emobility in Italy. Energy Policy 2013;57:506-17. doi:10.1016/j.enpol.2013.02.022.

[6] Giordano V, Gangale F, Fulli G. Smart Grid projects in Europe: lessons learned and current developments. 1st ed. Luxembourg: Publications Office of the European Union; 2011. doi: $10.2790 / 32946$.

[7] Colak I, Fulli G, Sagiroglu S, Yesilbudak M, Covrig C-F. Smart grid projects in Europe: Current status, maturity and future scenarios. Appl Energy 2015;152:58-70.

doi:10.1016/j.apenergy.2015.04.098.

[8] Simoes MG, Roche R, Kyriakides E, Suryanarayanan S, Blunier B, McBee KD, et al. A comparison of smart grid technologies and progresses in Europe and the U.S. IEEE Trans Ind Appl 2012;48:1154-62. doi:10.1109/TIA.2012.2199730.

[9] Lin CC, Yang CH, Shyua JZ. A comparison of innovation policy in the smart grid industry across the pacific: China and the USA. Energy Policy 2013;57:119-32. doi:10.1016/j.enpol.2012.12.028.

[10] Goluchowicz K, Blind K. Identification of future fields of standardisation: An explorative application of the Delphi methodology. Technol Forecast Soc Change 2011;78:1526-41. doi:10.1016/j.techfore.2011.04.014. 
[11] Okoli C, Pawlowski SD. The Delphi Method as a Research Tool : An Example, Design Considerations and Applications 1 Introduction 2 Overview of the Delphi method. Inf Manag 2004;42:15-29. doi:10.1016/j.im.2003.11.002.

[12] Geist MR. Using the Delphi method to engage stakeholders: A comparison of two studies. Eval Program Plann 2010;33:147-54. doi:10.1016/j.evalprogplan.2009.06.006.

[13] Luthra S, Kumar S, Kharb R, Ansari MF, Shimmi SL. Adoption of smart grid technologies: An analysis of interactions among barriers. Renew Sustain Energy Rev 2014;33:554-65. doi:10.1016/j.rser.2014.02.030.

[14] Parag Y, Sovacool B. Electricity market design for the prosumer era. Nat Energy 2016;1:1-6. doi:10.1038/nenergy.2016.32.

[15] Lee J, Kim Y, Hahn J, Seo H. Customer Energy Management Platform in the Smart Grid. Adv. Inst. Technol., Seoul: IEEE; 2012, p. 1-4. doi:10.1109/APNOMS.2012.6356063.

[16] Koliou E. Demand Response Policies for the Implementation of Smart Grids. Technische Universiteit Delft, 2016.

[17] Iqtiyaniilham N, Hasanuzzaman M, Hosenuzzaman M. European smart grid prospects , policies , and challenges. Renew Sustain Energy Rev 2017;67:776-90. doi:10.1016/j.rser.2016.09.014.

[18] Giordano V, Fulli G. A business case for smart grid technologies: A systemic perspective. Energy Policy 2012;40:252-9. doi:10.1016/j.enpol.2011.09.066.

[19] Hossain MS, Madlool NA, Rahim NA, Selvaraj J, Pandey AK, Faheem A. Role of smart grid in renewable energy: An overview. Renew Sustain Energy Rev 2016;60:1168-84.

doi:10.1016/j.rser.2015.09.098.

[20] Viscusi WK, Vernon JM, Jr. JEH. Economics of Regulation and Antitrust. Cambridge: The MIT Press; 2005.

[21] Pinto Junior HQ, De Almeida EF. Economia da Energia - Fundamentos Econômicos, Evolução Histórica e Organização Industrial. 1st ed. Rio de Janeiro: Campus; 2007.

[22] Nelson R. The Sources of Economic Growth. 1st ed. Cambridge: Harvard University Press; 1996.

[23] Freeman C, Soete L. Chapter 1 - Introduction. Econ. Ind. Innov. 3rd ed., Cambridge: MIT Press; 1997, p. 1-27.

[24] Dantas G. Alternativas de Investimento do Setor Sucroenergético Brasileiro para Aproveitamento de Bagaço e de Palha. UFRJ, 2013.

[25] Borrás S, Edquist C. The choice of innovation policy instruments. Technol Forecast Soc Change 2013;80:1513-22. doi:10.1016/j.techfore.2013.03.002.

[26] Sung B, Song WY. Causality between public policies and exports of renewable energy technologies. Energy Policy 2013;55:95-104. doi:10.1016/j.enpol.2012.10.063.

[27] International Energy Agency. Energy Technology Perspectives 2008: Scenarios \& Strategies to 2050. Paris: 2008.

[28] Kiss B, Neij L. The importance of learning when supporting emergent technologies for energy efficiency-A case study on policy intervention for learning for the development of energy efficient windows in Sweden. Energy Policy 2011;39:6514-24. doi:10.1016/j.enpol.2011.07.053.

[29] International Energy Agency. Technology Roadmap - Smart Grids. Paris: 2011.

[30] Siano P. Demand response and smart grids - A survey. Renew Sustain Energy Rev 2014;30:46178. doi:10.1016/j.rser.2013.10.022.

[31] Geels FW. The Dynamics of Transitions in Socio-technical Systems: A Multi-level Analysis of the Transition Pathway from Horse-drawn Carriages to Automobiles (1860-1930). Technol Anal Strateg Manag 2005;17:445-76. doi:10.1080/09537320500357319.

[32] Broman Toft M, Schuitema G, Thøgersen J. Responsible technology acceptance: Model development and application to consumer acceptance of Smart Grid technology. Appl Energy 
2014;134:392-400. doi:10.1016/j.apenergy.2014.08.048.

[33] Joskow P. Regulation of Natural Monopolies. Cambridge: 2005.

[34] Jamasb T, Pollitt M. Liberalisation and R \& D in network industries : The case of the electricity industry 2008;37:995-1008. doi:10.1016/j.respol.2008.04.010.

[35] Meeus L, Saguan M, Glachant J-M, Belmans R. Smart Regulation for Smart Grids. Firenze: 2010.

[36] Ruester S, Schwenen S, Batlle C, Pérez-Arriaga I. From distribution networks to smart distribution systems: Rethinking the regulation of European electricity DSOs. Util Policy 2014;31:229-37. doi:10.1016/j.jup.2014.03.007.

[37] Erlinghagen S, Markard J. Smart grids and the transformation of the electricity sector: ICT firms as potential catalysts for sectoral change. Energy Policy 2012;51:895-906. doi:10.1016/j.enpol.2012.09.045.

[38] Dantas G de A, de Castro NJ, Brandão R, Rosental R, Lafranque A. Prospects for the Brazilian electricity sector in the 2030s: Scenarios and guidelines for its transformation. Renew Sustain Energy Rev 2016:1-11. doi:10.1016/j.rser.2016.08.003.

[39] Connor PM, Baker PE, Xenias D, Balta-Ozkan N, Axon CJ, Cipcigan L. Policy and regulation for smart grids in the United Kingdom. Renew Sustain Energy Rev 2014;40:269-86. doi:10.1016/j.rser.2014.07.065.

[40] Crispim J, Braz J, Castro R, Esteves J. Smart Grids in the EU with smart regulation: Experiences from the UK, Italy and Portugal. Util Policy 2014;31:85-93. doi:10.1016/j.jup.2014.09.006.

[41] Gangale F, Mengolini A, Onyeji I. Consumer engagement: An insight from smart grid projects in Europe. Energy Policy 2013;60:621-8. doi:10.1016/j.enpol.2013.05.031.

[42] European Union (EU). Directive 2009/28/EC of the European Parliament and of the Council of 23 April 2009 on the promotion of the use of energy from renewable sources and amending and subsequently repealing Directives 2001/77/EC and 2003/30/EC. Brussels: 2009.

[43] Monypeny T. Implementation of Smart Grid Technology in the United States. Interdiscip J Undergrad Res 2013;2:11.

[44] McKenna E, Richardson I, Thomson M. Smart meter data: Balancing consumer privacy concerns with legitimate applications. Energy Policy 2012;41:807-14. doi:10.1016/j.enpol.2011.11.049.

[45] King N, Jessen P. For Privacy's Sake: Consumer "Opt-Outs" for Smart Meters. Oregon State Univ 2014;30:530-9. doi:10.1016/j.clsr.2014.07.001.

[46] CEER. Status Review of Regulatory Aspects of Smart Metering. Brussels: 2013.

[47] Cervigni G, Larouche P. Regulating Smart Metering in Europe: technological, Economic and Legal Challenges. Brussels: 2014.

[48] Ernst \& Young. Cost-Benefit Analysis for the Comprehensive Use of Smart Metering Systems. 2013.

[49] Cambini C, Meletiou A, Bompard E, Masera M. Market and regulatory factors influencing smartgrid investment in Europe: Evidence from pilot projects and implications for reform. Util Policy 2015;40:36-47. doi:10.1016/j.jup.2016.03.003.

[50] Jenkins C. RIIO Economics: examining the economics underlying Ofgem's new regulatory framework. 2011.

[51] Melo CA de, Jannuzzi G de M, Bajay SV. Nonconventional renewable energy governance in Brazil : Lessons to learn from the German experience. Renew Sustain Energy Rev 2016;61:22234. doi:10.1016/j.rser.2016.03.054.

[52] European Comission. Cost-benefit analyses \& state of play of smart metering deployment in the EU-27. Brussels: 2014.

[53] Buryk S, Mead D, Mourato S, Torriti J. Investigating preferences for dynamic electricity tariffs: The effect of environmental and system benefit disclosure. Energy Policy 2015;80:190-5. 
doi:10.1016/j.enpol.2015.01.030.

[54] International Energy Agency. The Power of Transformation - Wind, Sun and the Economics of Flexible Power Systems. Paris: 2014.

[55] International Energy Agency. Energy Technology Perspectives 2014 - Harnessing Electricity's Potential. Paris: 2014.

[56] Campoccia A, Dusonchet L, Telaretti E, Zizzo G. An analysis of feed'in tariffs for solar PV in six representative countries of the European Union. Sol Energy 2014;107:530-42. doi:10.1016/j.solener.2014.05.047.

[57] Hawkes A, Entchev E, Tzscheutschler P. A Comparative Review of Microgeneration Policy Instruments in OECD Countries. Munich: 2014.

[58] Aneel - Agência Nacional de Energia Elétrica. Resolução Normativa No. 482. Brasília: 2012.

[59] Camilo HF, Edgar M, Udaeta M, Gimenes AL, Aquiles J. Assessment of photovoltaic distributed generation - Issues of grid connected systems through the consumer side applied to a case study of Brazil. Renew Sustain Energy Rev 2016:1-8. doi:10.1016/j.rser.2016.12.099.

[60] Laverty DM, Morrow DJ, Best R, Crossley PA. Telecommunications for smart grid: Backhaul solutions for the distribution network. Power Energy Soc Gen Meet IEEE 2010:1-6. doi:10.1109/PES.2010.5589563.

[61] Agência Brasileira de Desenvolvimento Industrial. Mapeamento da Cadeia Fornecedora de TIC e de seus Produtos e Serviços para Redes Elétricas Inteligentes (REI). Brasília: 2014.

[62] Sioshansi FP. Why the Time Has Arrived To Rethink The Electric Business Model. Electr J 2012;25:65-74. doi:10.1016/j.tej.2012.09.003.

[63] Niesten E, Alkemade F. How is value created and captured in smart grids? A review of the literature and an analysis of pilot projects. Renew Sustain Energy Rev 2016;53:629-38. doi:10.1016/j.rser.2015.08.069.

[64] Shomali A, Pinkse J. The consequences of smart grids for the business model of electricity firms. J Clean Prod 2016;112:3830-41. doi:10.1016/j.jclepro.2015.07.078.

[65] Calvillo CF, Sánchez-Miralles A, Villar J. Energy management and planning in smart cities. Renew Sustain Energy Rev 2016;55:273-87. doi:10.1016/j.rser.2015.10.133.

[66] Neirotti P, De Marco A, Cagliano AC, Mangano G, Scorrano F. Current trends in smart city initiatives: Some stylised facts. Cities 2014;38:25-36. doi:10.1016/j.cities.2013.12.010.

[67] Ngar-yin Mah D, van der Vleuten JM, Chi-man Ip J, Ronald Hills P. Governing the transition of socio-technical systems: A case study of the development of smart grids in Korea. Energy Policy 2012;45:133-41. doi:10.1016/j.enpol.2012.02.005.

[68] Wissner M. ICT, growth and productivity in the German energy sector - On the way to a smart grid? Util Policy 2011;19:14-9. doi:10.1016/j.jup.2010.07.001.

[69] Greco S, Ehrgott M, Figueira JR. Multiple Criteria Decision Analysis - State of the Art Surveys. 2nd ed. New York: Springer-Verlag New York; 2016. doi:10.1007/978-1-4939-3094-4. 


\section{Appendix A - Survey Questions}

1) Taking into consideration the objective of "benefit the environment and human health", indicate the impact associated to each of the following policies:

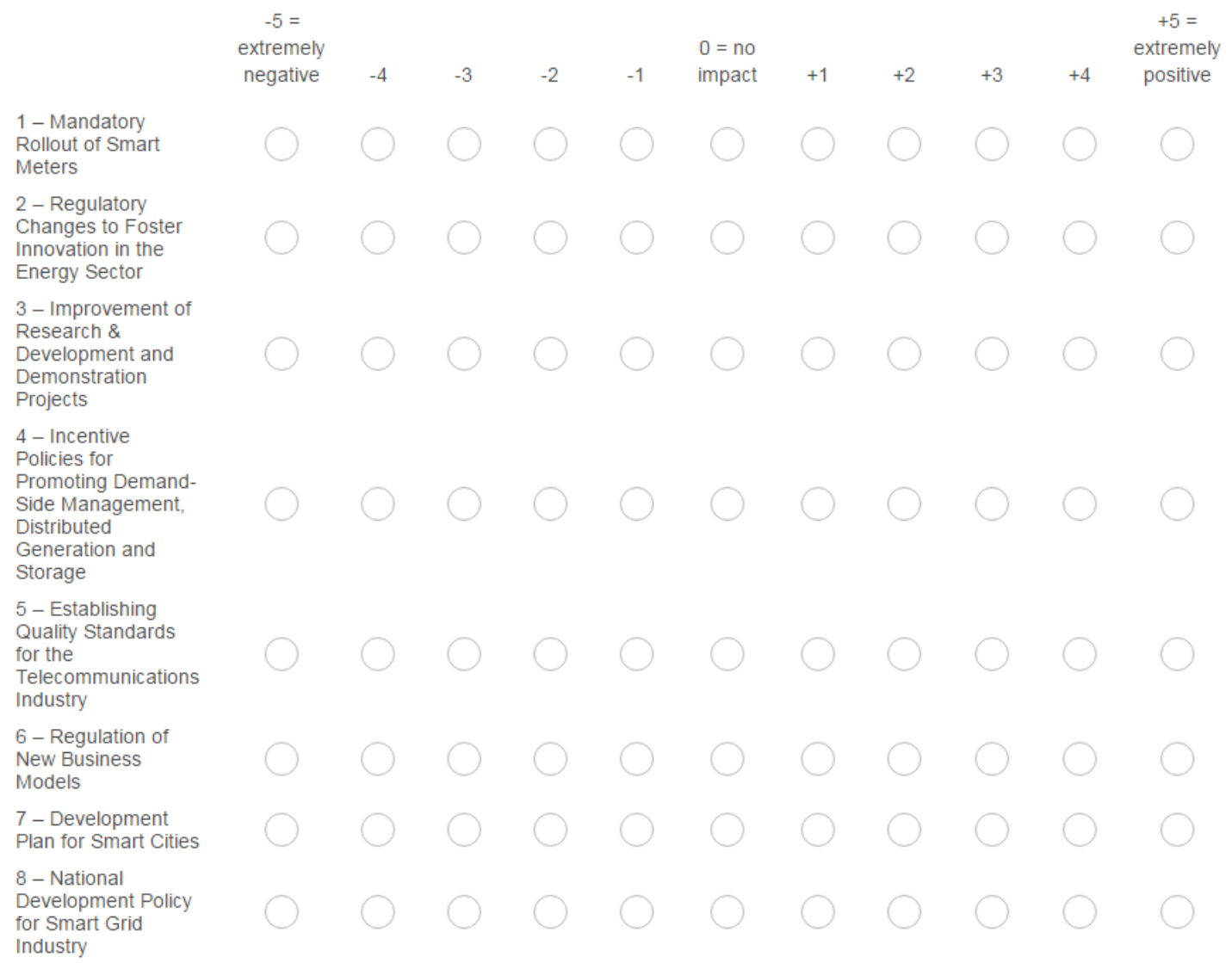

Fig. 1 Question \#1 of the first Delphi questionnaire.

8) Indicate your perspective on the relative importance of each of these objectives:

\begin{tabular}{|c|c|c|c|c|}
\hline $\begin{array}{c}0=\text { Not } \\
\text { Important }\end{array}$ & $\begin{array}{l}1 \text { = Slightly } \\
\text { Important }\end{array}$ & $\begin{array}{l}2=\text { Moderately } \\
\text { Important }\end{array}$ & $3=1 \mathrm{mportan} t$ & $\begin{array}{l}4=\text { Very } \\
\text { Important }\end{array}$ \\
\hline
\end{tabular}

Objective 1: benefit
the environment and human health

Objective 2: enhance

flexibility and

capabilities of the

system technological

infrastructure

Objective 3: ensure security of supply

Objective 4: ensure openness, fairness, transparency and

efficiency of markets

Objective 5: provide financial benefit to

the agents involved

Objective 6: provide economic and social benefit to the country

Objective 7 : ensure

executability and

promote the adoption

of technological

innovations

Fig. 2 Question \#8 of the first Delphi questionnaire. 
1) Taking into consideration the objective of "benefit the environment and human health", indicate the impact associated to each of the following policies:

\begin{tabular}{|c|c|c|c|c|}
\hline & (AM) & (SD) & $-5-4-3-2-1$ & $0+1+2+3+4+5$ \\
\hline 1-Mandatory Rollout of Smart Meters & 1,41 & 2,18 & & \\
\hline 2 - Regulatory Changes to Foster Innovation in the Energy Sector & 3,00 & 1,56 & & \\
\hline 3-Improvement of Research \& Development and Demonstration Projects & 2,64 & 1,50 & & \\
\hline $\begin{array}{l}4 \text { - Incentive Policies for Promoting Demand-Side Management, Distributed } \\
\text { Generation and Storage }\end{array}$ & 3,51 & 1,59 & & \\
\hline 5 - Establishing Quality Standards for the Telecommunications Industry & 2,37 & 1,80 & & \\
\hline 6-Regulation of New Business Models & 2,64 & 1,79 & & \\
\hline 7 - Development Plan for Smart Cities & 3,78 & 1,38 & & 8 \\
\hline 8- National Development Policy for Smart Grid Industry & 3,33 & 1,62 & & 8 \\
\hline
\end{tabular}

Fig. 3 Feedback provided to the experts in the second questionnaire. 